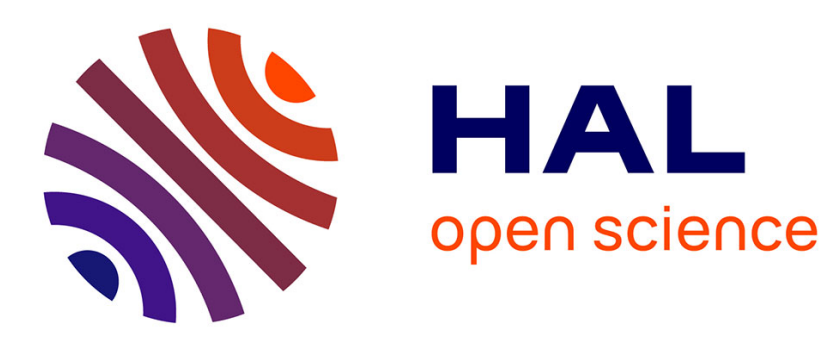

\title{
Sign Language and the Foundations of Anaphora Philippe Schlenker
}

\section{To cite this version:}

Philippe Schlenker. Sign Language and the Foundations of Anaphora. Annual Review of Linguistics, 2015, 3 (1), pp.149-177. 10.1146/annurev-linguistics-011415-040715 . hal-03052095

\section{HAL Id: hal-03052095 https://hal.science/hal-03052095}

Submitted on 10 Dec 2020

HAL is a multi-disciplinary open access archive for the deposit and dissemination of scientific research documents, whether they are published or not. The documents may come from teaching and research institutions in France or abroad, or from public or private research centers.
L'archive ouverte pluridisciplinaire HAL, est destinée au dépôt et à la diffusion de documents scientifiques de niveau recherche, publiés ou non, émanant des établissements d'enseignement et de recherche français ou étrangers, des laboratoires publics ou privés. 


\title{
Sign Language and the Foundations of Anaphora*
}

\author{
Philippe Schlenker** \\ (Institut Jean-Nicod, CNRS; New York University)
}

First draft (references corrected), June 10, 2015

\begin{abstract}
On the surface, sign language anaphora is often realized very differently from its spoken language counterpart. In simple cases, an antecedent is associated with a position or 'locus' in signing space, and an anaphoric link is obtained by pointing towards that locus to recover its semantic value. It has been argued that this mechanism is sometimes an overt realization of the device of coindexation in formal syntax and semantics. Summarizing some recent semantic work, we discuss two kinds of insights that sign language research can bring to the foundations of anaphora. First, in some cases the overt nature of indices in sign language makes it possible to bring overt evidence to bear on classic debates in semantics. We consider two: the first concerns the availability of situation-denoting variables in natural language (we argue that pointing signs can be situationdenoting in addition to being object-denoting); the other concerns the availability of binding without c-command (we suggest that sign language provides overt evidence for such a possibility). Second, in some cases sign language pronouns raise new challenges for formal semantics. In a nutshell, the challenge is that loci may simultaneously function as formal variables and as simplified depictions of what they denote - which requires the construction of a formal semantics with iconicity to analyze their properties.
\end{abstract}

\footnotetext{
* The research leading to these results received funding from the European Research Council under the European Union's Seventh Framework Programme (FP/2007-2013) / ERC Grant Agreement N³24115FRONTSEM (PI: Schlenker). Research was conducted at Institut d'Etudes Cognitives, Ecole Normale Supérieure - PSL Research University. Institut d'Etudes Cognitives is supported by grants ANR-10-IDEX0001-02 PSL* and ANR-10-LABX-0087 IEC. The research reported in this piece also contributes to the COST Action IS1006.

Most ASL and LSF data are cited from earlier publications; those by the author were conducted with ASL consultant Jonathan Lamberton and LSF consultants Yann Cantin and Ludovic Ducasse. Lamberton is also a coauthor of some articles cited below. Example (8) was elicited with Lamberton for this piece. References were prepared or corrected by Lucie Ravaux.

Relation to prior work: This piece summarizes earlier published results and borrows (in form and substance) from some of the author's earlier works (some of them co-authored). Sources are indicated at the beginning of each paragraph. Two survey papers play a role throughout this piece: Schlenker 2013b, and the longer piece on sign language semantics cited as Schlenker $2015 \mathrm{~b}$.

Institut Jean-Nicod - CNRS, UMR 8129, ENS/EHESS - PSL Research University F-75005 Paris, France. Department of Linguistics, New York University.
} 
In this summary of recent research on sign language semantics, we discuss three cases in which sign languages can bring new insights into the foundations of anaphora. These cases are of two types.

- First, we re-visit two classic semantic debates. One concerns reference to times and worlds (or situations); the other concerns the nature of variable binding. In both cases, we suggest that the realization of sign language pronouns provides direct and overt evidence in favor of certain facts that must be inferred rather indirectly in most spoken languages. The argument is based on the observation that sign language can arguably realize overtly logical variables or 'indices', which are covert in spoken language (we also discuss some challenges to this view).

- Second, we suggest that some iconic properties of sign language pronouns argue for a renewed view of semantic interpretation: in some cases, some geometric properties of signs appear to directly reflect properties of their denotations, which argues for a condition of 'formal iconicity' at the very core of a formal semantic account. ${ }^{1}$

Loci as Variables

\subsection{Variable Visibility}

Sentences such as (1)a and (2)a can be read in three ways, depending on whether the embedded pronoun is understood to depend on the subject, on the object, or to be deictic.

(1) a. Sarkozy $\mathrm{i}_{\mathrm{i}}$ told Obama $\mathrm{O}_{\mathrm{k}}$ that he $\mathrm{i}_{\mathrm{ik} / \mathrm{m}}$ would be re-elected.

b. Sarkozy $\lambda$ i Obama $\lambda \mathrm{k}_{\mathrm{i}}$ told $\mathrm{t}_{\mathrm{k}}$ that $\mathrm{he}_{\mathrm{i} / \mathrm{k} / \mathrm{m}}$ would be re-elected.

(2) a. [A representative $]_{i}$ told [a senator $]_{k}$ that he $\mathrm{i}_{\mathrm{i} k / \mathrm{m}}$ would be re-elected.

b. [a representative $]_{i} \lambda i[\text { a senator }]_{k} \lambda k t_{i}$ told $t_{k}$ that he $e_{i k / m}$ be re-elected

These ambiguities have been analyzed in great detail in frameworks that posit that pronouns have the semantics of variables, which may be bound by a quantifier, or free - in which case they receive their value from an assignment function provided by the context. For instance, in the textbook analysis of Heim and Kratzer 1998, one way to represent the ambiguity of (1)a is through the representation in (1)b, where a bona fide Logical Form is obtained by choosing the index $i, k$ or $m$ for the pronoun he (since the subject and object are referring expressions, there are several alternative ways to represent the ambiguity). (2)b summarizes three possible representations of (2)a within the same framework, depending on whether he is given the index $i, k$ or $m$.

Sometimes these representations can get quite complex, for instance to capture the fact that plural pronouns may be simultaneously bound by several quantifiers, as in (the relevant reading of) (3)a, represented as in (3)b.

(3) a. [A representative $]_{\mathrm{i}}$ told [a senator $]_{\mathrm{k}}$ that they $\mathrm{y}_{\mathrm{i}, \mathrm{k}}$ would (both) be re-elected.

b. [a representative $]_{i} \lambda i$ [a senator $]_{k} \lambda k \quad t_{i}$ told $t_{k}$ that they ${ }_{i+k}$ would be re-elected

In this case, it is essential on the relevant reading that they should be simultaneously dependent on $a$ representative and on a senator, hence the 'sum' index $i+k$ that appears on they in (3)b.

While it is clear that a sentence such as (2)a is ambiguous, it is not at all uncontroversial that its readings should be captured by way of invisible indices that are nonetheless cognitively and semantically real. In fact, following in part Quine 1960, a movement of 'variable-free semantics' has proposed to analyze such ambiguities without recourse to variables (e.g. Jacobson 1999, 2012).

\footnotetext{
${ }^{1}$ Glossing conventions: In the following, sign language sentences are glossed in capital letters, as is standard. Expressions of the form WORD-i,WORD $D_{i}$ and $[\ldots E X P R E S S I O N \ldots]_{i}$ indicate that the relevant expression is associated with the locus (= position in signing space) $i$. A suffixed locus, as in WORD-i, indicates that the association is effected by pointing; a subscripted locus, as in $W O R D_{i}$ or $[\ldots E X P R E S S I O N \ldots]_{i}$, indicates that the relevant expression is signed in position $i$. Locus names are assigned from right to left from the signer's perspective; thus when loci $a, b, c$ are mentioned, $a$ appears on the signer's right, $c$ on the left, and $b$ somewhere in between (special conventions will be introduced for high and low loci when relevant). Pronouns, glossed as $I X$ (for 'index'), can point back towards previously established loci, and are glossed as $I X-i$ if they point towards - or 'index' - locus $i$; the numbers 1 and 2 correspond to the positions of the signer and addressee respectively. Agreement verbs include loci in their realization - for instance the movement realizing $a, b-M E E T$ starts out from the two loci $a$ and $b$, and means that the individuals denoted by these loci met. When an expression indexes a default locus, it is usually written without a letter index (e.g. $I X$ rather than $I X-a$ ). $C L_{a}$ stands for a classifier signed in locus $a$. IX-arc- $a$ refers to a plural pronoun indexing locus $a$. Specifications are sometimes added to distinguish different classifiers - e.g. CL-hang stands for a classifier denoting a person in hanging position. Finally, rep is used when an expression is repeated.

In most cases we omit non-manual expressions and manual modulations; when non-manual modulations are encoded, they appear on a line above the signs they modify, and ${ }^{\wedge}$ encodes raised eyebrows, while $\sim$ encodes lowered eyebrows.
} 
In this section, we survey recent results that suggest that sign language displays an overt version of something close to the indices of (1)-(3), and that this fact can be used to revisit some foundational questions in semantics. However, it will prove useful to distinguish between two versions of this 'Hypothesis of Variable Visibility'. According to the Weak Version, it is possible to associate a certain a position in signing space or 'locus' to a pronoun and to its antecedent in order to mark their dependency; and to associate different such positions or 'loci' to different deictic pronouns if they denote different objects. According to the Strong Version, loci really do display the behavior of variables - which as we will see below is a strictly stronger (and possibly overly strong) claim. ${ }^{2}$

(4) Variable Visibility

a. Weak Version

In sign language, loci in signing space can be associated both to an arbitrary number of pronouns and to their antecedents to mark their dependency. Furthermore, deictic pronouns that refer to different objects may be associated to different loci.

b. Strong Version

In sign language, some uses of loci display the behavior of logical variables, both in their bound and in their free uses.

We will establish the plausibility of Variable Visibility (Section 1.2), and then we will use it to revisit two foundational debates in semantics: First, are there time and world variables (Section 1.3)? Second, can variables be dynamically bound (Section 1.4)? We will sketch a positive answer to both questions: first, the various versions of the pointing sign can have temporal and modal in addition to nominal uses; second, the dependency between pronouns and their antecedents made visible by loci behaves very much like dynamic binding, including in some cases in which (some) Etype approaches and dynamic approaches make different predictions. We will then revisit the choice between the Weak and the Strong Version of Variable Visibility by discussing data due to Kuhn (to appear), who argues that loci display some properties that are unexpected of bona fide variables, but expected if these are treated instead as features (Section 1.5).

\subsection{Loci as variables ${ }^{3}$}

Lillo-Martin and Klima 1990 argued that logical variables or 'indices', which are usually covert in spoken languages, can be overtly realized in sign language by positions in signing space or 'loci'. In case a pronoun is used deictically or indexically, its locus usually corresponds to the actual position of its denotation, be it the speaker, the addressee, or some third person (e.g. Meier, to appear). If the pronoun is used anaphorically, the antecedent typically establishes a locus, which is then 'indexed' (= pointed at) by the pronoun. In (5)a (ASL), the sign names Bush and Obama establish loci by being signed in different positions; in (5)b, the antecedent Noun Phrases are accompanied with pointing signs that establish the relevant loci. In quantificational examples, indexing disambiguates among readings, as in (6) (LSF).

(5) a. IX-1 KNOW BUSH IX-1 KNOW OBAMA $_{\mathrm{b}}$. IX-b SMART BUT IX-a NOT SMART.

'I know Bush and I know Obama. He [= Obama] is smart but he [= Bush] is not smart.'

b. IX-1 KNOW PAST PRESIDENT IX-a IX-1 KNOW NOW PRESIDENT IX-b. IX-b SMART BUT

IX-a NOT SMART.

'I know the former President and I know the current President. He [= the current President] is smart but he [=the former President] is not smart.'

(ASL; 4, 179; Schlenker 2011)

(6) DEPUTY DENATOR $_{\mathrm{a}} \mathrm{CL}_{\mathrm{b}}$-CL SE $_{\mathrm{a}}$ IX-b a-TELL-b IX-a / IX-b WIN ELECTION

'An $\mathrm{MP}_{\mathrm{b}}$ told a senator $\mathrm{a}_{\mathrm{a}}$ that $\mathrm{he}_{\mathrm{a}} / \mathrm{he}_{\mathrm{b}}$ (= the deputy) would win the election.' (LSF; 4, 233)

The cases we just discussed involved singular loci. But when a pronoun denotes a plurality, it can be realized by an 'arc' pointing sign, which thus indexes a semi-circular area; and there are also dual and even trial pronouns when the pronoun denotes two or three individuals. Strikingly, these pronouns can simultaneously index several loci in cases corresponding to the 'split antecedents' discussed in (3). Thus in (7), the dual pronouns THE-TWO-a,b is realized as a horizontal 2 that goes back and forth between the two loci; and it can be checked that this is no accident: if the position of the loci is modified, the movement that realizes THE-TWO changes accordingly.

(7) IX-1 HAVE TWO TICKET. IF 1-GIVE JOHN ${ }_{\mathrm{a}}$ BILL $_{\mathrm{b}}$, THE-TWO-a,b HAPPY.

'I have two tickets. If I give them to John and Bill, they will be happy.' (ASL; 2,180 )

\footnotetext{
${ }^{2}$ In Section 1.5, we will discuss the possibility, raised by Kuhn, to appear, that loci should be viewed as agreement markers rather than as a variables; while such agreement markers will have the ability to disambiguate the relevant readings, they will not share other properties that one expects to find in logical variables.

${ }^{3}$ This section borrows from Schlenker et al. 2013 and Schlenker 2014a, 2014b.
} 
More complex cases can easily be constructed, with trial or plural pronouns indexing more than two loci.

A crucial property of sign language anaphora is that loci can be created 'on the fly' in many different positions of signing space, and that there is no clear upper bound on the number of loci that can simultaneously be used, besides limitations of performance (since signers need to be able to distinguish loci from each other, and to keep their position and denotation in memory). Now there are spoken languages in which third person reference can be disambiguated by grammatical means, for instance by way of a distinction between proximate and obviative marking (in Algonquian, see Hockett 1966) or in switch-reference systems (e.g. Finer 1985). But these only make it possible to distinguish among a small number of third person elements - typically two or three (for instance, 'proximate', 'obviative', and sometimes 'double obviative' in obviative systems). By contrast, there seems to be an unlimited of potential distinctions in sign language. An example with 7 loci is given in (8) (with the loci boldfaced): besides the speaker and addressee (glossed as 1 and 2 respectively), there are five third person loci ranging from $a$ (right-most) to $e$ (left-most). Each of these 5 loci is explicitly introduced by the antecedent Noun Phrase (by way of a pointing sign co-occurring with it), and retrieved in the last sentence by a pointing sign as well (for the first member of each list), or just by way of a word signed in the relevant position. (Here and in later examples, when a superscripted score precedes a sentence, it is an acceptability judgment on a 7-point scale, with $7=$ best; reference to the relevant video follows the example.)

Context: The speaker and addressee have conducted individual interviews with the same students. They were asked to provide a ranking.

${ }^{7}$ REMEMBER. LAST YEAR THE-TWO-1,2 CL-ONE-COME-COME INTERVIEW 5 EUROPE STUDENT . THE-TWO-1,2 MUST PONDER CHOOSE BEST (LIST) $1^{\text {ST }} 2^{\text {ND }}$ AND-SO-ON. IX-1 DECIDE FIRST IX-a FRENCH STUDENT, SECOND IX-b GERMAN, THIRD IX-c ITALIAN, FOURTH IX-d SPANIARD, FIFTH IX-e PORTUGUESE.

IX-2 OPPOSITE IX-2 DECIDE IX-e FIRST-e, SECOND-d, THIRD-c, FOURTH-b, FIFTH-a.

'Remember? Last year, the two of us interviewed five European students. We had to come up with a ranking. I thought the French student was \#1, the German student was \#2, the Italian student was \#3, the Spanish student was \#4, and the Portuguese student was \#5. To the contrary, you thought the Portuguese student was \#1, the Spanish student was \#2, the Italian student was \#3, the German student was \#4, and the French student was \#5. (ASL, 32,0118)

Since there appears to be an arbitrary number of possible loci, it was suggested that these do not spell out morpho-syntactic features, but rather are the overt realization of formal indices (LilloMartin and Klima 1990, Sandler and Lillo-Martin 2006; we revisit this point in Section 1.5). While pointing can have a variety of uses in sign language (Sandler and Lillo-Martin 2006, Schlenker 2011a), for simplicity we will restrict attention to anaphoric uses, which involve locus establishment by an antecedent (for anaphoric uses), and retrieval of this locus to realize a pronoun. ${ }^{4}$ Importantly, despite the difference in surface realization, there are some striking similarities between sign language pronouns and their spoken counterparts, which makes it desirable to offer a unified theory:

- Sign language pronouns obey at least some of the syntactic constraints on binding studied in syntax. For instance, versions of the following rules have been described for ASL (Lillo-Martin 1991, Sandler and Lillo-Martin 2006, Koulidobrova 2011, Schlenker and Mathur 2013): Condition A, which mandates that a reflexive pronoun such as himself corefer with a local antecedent (e.g. $\mathrm{He}_{i}$ admires himself $f_{i}$ ); Condition B, which prohibits a non-reflexive pronoun from overlapping in reference with a local antecedent (hence the deviance of \#He admires $_{\text {him }}$, understood with coreference); and Strong Crossover, which prohibits a quantificational expression from moving to the left of a coindexed pronoun that c-commands its base position (hence the deviance of \#[Which man $]_{i}$ does he ${ }_{i}$ think I will hire $t_{i}$, where $t_{i}$ is the base position of the interrogative expression, and $h e_{i}$ is coindexed with it).

- In simple cases, the same ambiguity between strict and bound variable readings is found in both modalities (see Sandler and Lillo-Martin 2006; further cases are alluded to in Section 2.5): ${ }^{5}$

(9) IX-1 POSS-1 MOTHER LIKE. IX-a SAME-1, a.

Ambiguous: I like my mother. He does too [= like my / like his mother] (ASL; 1, 108)

\footnotetext{
${ }^{4}$ Besides their function to establish and to retrieve loci, pointing signs have been argued to have several other functions; in particular:

(i) Bahan et al. 1995 argue that in some cases an index plays the role of a definite determiner.

(ii) It has sometimes been claimed that pointing can be used solely for purposes of 'comparing' two situations (e.g. in Winston 1995).

5 In order to provide a formal treatment of (9), we would need to posit a rule of 'locus erasure' - a point we return to in Section 1.5.
} 
- In addition, the same cases of 'donkey anaphora', or apparent binding without c-command, are found in sign and in spoken language (Schlenker 2011b) - a point we will explore in Section 1.4.

It is thus a reasonable hypothesis that the pronominal systems of sign and spoken language share at least a common core. We will now explore cases in which sign language loci arguably provide evidence for specific conclusions in some foundational debates pertaining anaphora.

\subsection{Individual, time and world variables ${ }^{6}$}

We start with the debate concerning the existence of an abstract anaphoric mechanism that applies in similar fashion to the nominal, temporal and modal domains. In a nutshell, we argue that ASL loci have all three uses, and thus provide an argument in favor of the existence of such an abstract system. In what follows, it will be a good rule of thumb to take temporal and modal uses of the pointing sign to have roughly the same meaning as the English word then, which has both temporal and modal uses; the crucial difference is that in ASL the very same word can have nominal, temporal and modal uses (and locative uses as well, as we will see shortly); and that it arguably 'wears its indices on its sleeves' because of the variable-like uses of loci.

The point is by no means trivial. In the tradition of modal and tense logic, it was thought that expressions are only implicitly evaluated with respect to times and possible worlds: language was thought to be endowed with variables denoting individuals, but not with variables denoting times or possible worlds. By contrast, several researchers argued after Partee 1973 and Stone 1997 that natural language has time- and world-denoting variables - albeit ones that manifest themselves as affixes (tense, mood) rather than as full-fledged pronominal forms. In other cases (e.g. the word then in its temporal and modal uses), it is reasonable to posit that spoken language does have an overt temporal/modal pronoun (Iatridou 1994, Izvorski 1996, Schlenker 2004, Bhatt and Pancheva 2006), but that it happens to be pronounced differently from individual-denoting pronouns. Now if a single abstract anaphoric system is indeed at work across the nominal, temporal and modal domains, one might expect that some languages have a single pronoun that can be used across categories. It has been argued before that there are indeed morphological or syntactic similarities across these categories (Bittner 2001, Bhatt and Pancheva 2006). Here we make the simple suggestion that ASL pronouns in their various forms can have nominal, temporal, modal and also locative uses.

The full argument has three steps:

1. As we discussed above, nominal anaphora in sign language usually involves (i) the establishment of positions in signing space, called 'loci', for antecedents; (ii) pointing towards these loci to express anaphora. Both properties are also found in the temporal and modal domains.

2. This observation doesn't just hold of the singular index; temporal uses of dual (illustrated in (7)), trial and plural pronouns can be found as well. The phenomenon is thus general and it is not plausible to posit that it is an accident that all these morphologically distinct pronouns simultaneously have nominal, temporal and modal uses: indexing per se seems to have all these uses.

3. Temporal and modal anaphora in ASL can give rise to patterns of inference that are characteristic of so-called 'donkey' pronouns (i.e. pronouns that depend on existential antecedents without being in their syntactic scope).

Here we will focus on the first two steps of the argument, and suggest by way of translations that the inferences in 3. are indeed obtained (see Schlenker 2013a for further details).

- Temporal indexing: In (10)a,b, the normal pronoun $I X-a$ and the dual pronoun THE-TWO- $a, b$ are bound by existential quantifiers in the preceding sentence. The pattern is the same as was described for nominal anaphora in (6): existential antecedents establish loci; pronominal forms retrieve them by way of pointing; furthermore, this applies both to normal and to dual pronouns, which may simultaneously be dependent on several antecedents. The examples we discuss involve anaphora to an existential quantifier in a preceding sentence, and they do give rise to the same (so-called 'donkey') readings as in spoken languages. ${ }^{7}$

(10) a. Context: Every week I play in a lottery.

7 IX-1 ${ }_{a}$ [SOMETIMES WIN]. IX-1 ${ }_{\mathrm{b}}[$ SOMETIMES LOSE]. $\quad \quad \quad \hat{\mathrm{I}} \hat{\mathrm{X}}-\mathrm{a}$ IX-1 HAPPY.

'Sometimes I win. Sometimes I lose. Then [= when I win] I am happy.' (ASL; 7, 204)

b. Context: Every year, the speaker plays in the lottery.

\footnotetext{
${ }^{6}$ This section borrows from Schlenker 2013a, b.

${ }^{7}$ Importantly, loci appear in the usual signing space, which is in front of the signer. Although the words for tomorrow and yesterday are signed on the 'time line', which is on a sagittal plane (tomorrow is signed in the front, yesterday towards the back), no pointing occurs towards it, at least in this case (but see Emmorey 2002 for discussion).
} 
6.5 SOMETIMES IX-1 ${ }_{a}$ [VERY LUCKY]. SOMETIMES ${ }_{b}[$ LITTLE-BIT LUCKY].

NO-MATTER THE-TWO-a, $\mathrm{b}$ IX-1 HAPPY.

'Sometimes I am very lucky. Sometimes I am a little lucky. In both cases, I am happy.' (ASL; 7, 212)

(Schlenker, 2013a)

- Modal Indexing: While there are no clear world indexicals or world proper names, modals such as can are standardly analyzed as existential quantifiers over possible worlds (e.g. Kratzer 1991). Here too we replicate the patterns we saw in the nominal domain, as well as in the temporal domain:

(11) a. Context: The speaker is playing in a lottery.

6.8 NOW IX-1 ${ }_{a}$ [POSSIBLE RICH]. ${ }_{b}[$ POSSIBLE SAME POOR]. $\quad \overline{\mathrm{IX}} \overline{-}-\mathrm{a}$ IX-1 LUCKY.

'Now I might be rich. I might also still be poor. Then [= if I am rich] I am lucky.' (ASL; 7, 196)

b. Context: The speaker is playing in a lottery, and he believes he has won.

6.5 NOW IX-1 POSSIBLE ${ }_{a}$ [VERY RICH]. POSSIBLE ${ }_{b}[$ LITTLE-BIT RICH]. NO-MATTER

THE-TWO-a, b IX-1 LUCKY.

'Now I might be rich, and I might be a little rich. In both cases I am lucky.' (ASL; 7, 210)

(Schlenker 2013a)

We conclude that explicit anaphoric reference to times and possible worlds is attested in ASL though our analysis leaves it open whether times and worlds should be primitive types of entities in our ontology, or should be treated as varieties of a more general category of situations.

While the argument could stop here, the sign language data argue for a further conclusion, namely that temporal and modal reference might be more similar to locative reference than to individual reference. The argument hinges on a peculiarity of locative reference in ASL and LSF: when an individual has been associated with a spatial location in previous discourse, one can refer to him by pointing towards the locus associated with that location (though pointing to the original locus of the individual is often possible too). To illustrate, let us consider first the locative example in (12). The loci $a$ (on the signer's right) and $b$ (on the signer's left) are respectively associated with FRENCH CITY and AMERICAN CITY in the first sentence. But in the second sentence, the pronouns in bold, which index these loci, refer to John rather than to these locations. Intuitively, they can be thought of as referring to John-in-the-French-city vs. John-in-the-American-city (a point to which we return below).

\section{(12) Locative Shift}

JOHN [WORK IX-a FRENCH CITY] $]_{a}$ SAME [WORK IX-c AMERICA CITY] .

\section{$\overline{\mathrm{I} X}-\overline{\mathrm{X}}-\mathrm{a}$ IX-1 $\mathrm{a}^{8}$ HELP IX-a+ ${ }^{9}, \hat{\mathrm{I}} \overline{\mathrm{X}}-\mathrm{b}$ IX-1b NOT HELP IX-b+.}

'John does business in a French city and he does business in an American city.

There [= in the French city] I help him. There [= in the American city] I don't help him.'

(ASL, 4, 66; Schlenker 2013a)

Strikingly, similar facts hold in the temporal domain. In the first sentence of (13), the loci $a$ (on the signer's right) and $c$ (on the signer's left) are respectively associated with times at which John was a college student and a college professor; $J O H N$ is associated with locus $b$, in the middle. In the second sentence, however, the pronouns in bold index the same loci but refer to John rather than to time periods.

(13) Temporal Shift

Context: John is retired.

JOHN IX-b [FORMER COLLEGE STUDENT] $]_{\mathrm{a}}$ [FORMER COLLEGE PROFESSOR PERSON] $]_{\mathrm{c}}$.

\section{$\overline{\mathrm{IX}-\mathrm{a}}$ IX-1a HELP IX-a+, $\overline{\mathrm{IX}}-\overline{\mathrm{A}}-\mathrm{c}$ IX-1c NOT HELP IX-c+}

'At some point John was a college student and at some point he was a university professor.

Then [=when he was a student] I helped him. Then [= when he was a professor] I didn't help him.'

(ASL, 4, 68; Schlenker 2013a)

The same pattern is found in the modal domain:

\footnotetext{
${ }^{8} l a$ and $l c$ are positions close to the signer, but to his right and to his left respectively.

${ }^{9}$ We write $a+$ and $c+$ to indicate that pointing is towards a position slightly higher than loci $a$ and $c$ (see Schlenker 2013a for discussion).
} 
(14) Modal Shift

Context: I don't know who John is.

JOHN IX-b [POSSIBLE COLLEGE STUDENT $]_{\mathrm{a}}[\text { POSSIBLE COLLEGE PROFESSOR PERSON] }]_{\mathrm{c}}$.

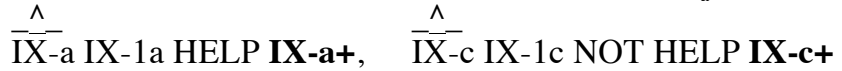

'It's possible that John is a college student and it's possible that he is a university professor.

Then [= if he is a student] I will help him. Then [= if he is a professor] I won't help him.'

(Inf 1, 4, 72; Schlenker 2013a)

The loci $a$ and $c$, which are initially associated with possible situations in which John is a college student and a college professor respectively, are used in the second sentence to refer to John himself.

There are two possible conclusions that one could draw from these observations. One is that locative, temporal and modal anaphora form a natural class which is somewhat different from individual anaphora. This might for instance be because the 'primitive elements' of natural language ontology include individuals on the one hand, and a broad class of 'situations' on the other - with locative, temporal and nominal anaphora as subspecies of situation anaphora. An alternative possibility is that it is just because individuals can naturally be taken to be situated at locations, times and worlds that individual loci undergo locative shift.

Irrespective of the issues raised by locative shift, our main conclusion is that a single anaphoric system, based on locus indexing, makes it possible to realize nominal, temporal and modal anaphora - as well as locative anaphora, as we just saw. Importantly, it is too early to tell whether it is the signed modality per se that makes it possible to have such all-purpose anaphoric devices. It might be a grammatical accident of ASL that the pointing sign, in its various incarnations (singular dual, trial and plural forms), can have all these uses. If so, it should be possible in principle to find a spoken language with a pronoun underspecified in exactly the same way; in essence, such a pronoun would fulfill both the functions of he/she/it and of then. Another possibility is that there is something essential about loci - for instance the fact that they can serve as 'pure' logical variables - which allows them to have nominal, temporal, modal and locative uses alike. We leave this question open, and turn to case of visibility which is arguably connected in a more essential way to the signed modality.

\subsection{Dynamic variables ${ }^{10}$}

As we noted at the outset, if loci can be the overt realization of some variables, binding relations, which must be inferred in spoken languages, can be made overt in sign languages. Specifically, by virtue of the device of locus establishment and retrieval, the connection between pronouns and their antecedents is sometimes made formally explicit in sign language. This matters because the nature of the relation between a pronoun has been hotly debated in the literature of spoken languages.

The debate concerns the role of c-command (or 'scope', in traditional logical terminology) in the establishment of a binding relation between a pronoun and a quantificational antecedent. In some cases, it seems that such a relation is necessary. No man drinks if he drives has a meaning akin to no man $x$ is such that $x$ drinks if $x$ drives, and he does appear in the scope of no man, as shown in (15)a. By contrast, If no man drinks, he drives does not allow the pronoun to be dependent on no man because he is not in the scope of no man, as shown in (15)b (to be felicitous, he would have to refer to some salient individual).

\section{(15) Scope in English I}

A pronoun must (usually) be in the scope of [= 'c-commanded by'] a quantifier it depends on.

a. No man drinks if he drives.



b. If no man drinks, he drives.

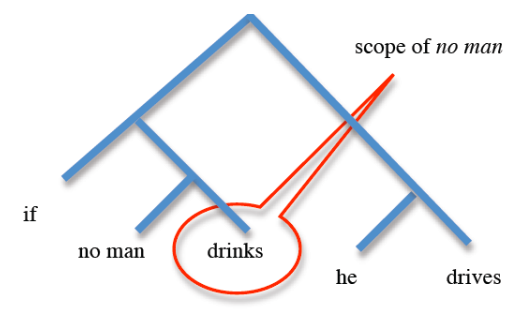

When no man is replaced with a man, however, the facts change. If a man drinks, he suffers is naturally interpreted as: If a man drinks, that man suffers; the pronoun is dependent on the quantifier although it is not within its scope, as shown in (16).

\footnotetext{
${ }^{10}$ This section borrows from Schlenker 2011b,c, 2013b.
} 
(16) Scope in English II

A pronoun can depend on an existential quantifier without being in its scope.



Because Geach 1962 originally discussed examples such as (17)a-b to show that a pronoun may depend on a quantifier without being in its scope, pronouns that have this property are called 'donkey pronouns' in the literature.

(17) a. Every farmer who owns a donkey beat it.

b. If a farmer owns a donkey, he beats it.

There have been two reactions to the problem of 'donkey pronouns'.

1. Dynamic Semantics: One view is that the logic underlying natural language is just different from standard logic. An entire movement, called 'dynamic semantics', developed new rules that make it possible for a variable or a pronoun to depend on an existential quantifier or an indefinite without being in its scope (this may be done by treating indefinites themselves as variables, as in Kamp 1981 and Heim 1982; or by allowing existential quantifiers to bind outside of their syntactic scope, as in Groenendijk and Stokhof 1991).

2. E-type analysis: The opposing view is that no new logic is needed for natural language because the assimilation of pronouns to variables is incorrect. On this view, the pronoun he in (16) should be analyzed as a concealed description such as the man, or the man who drinks (e.g. Evans 1980; Heim 1990; Elbourne 2005); analyses that make this assumption are called 'E-type theories'. In some Etype theories, the pronoun is literally taken to come with an elided noun - for instance, in this case he $=$ he man, where man is unpronounced and he is a version of the (this identity is morphologically realized in German, where der means both the and he) (Elbourne 2005). In other E-type theories, the pronoun is taken to have a richer semantic content, with for instance he $=$ the man who drinks (e.g. Heim 1990). We henceforth restrict attention to the former analysis (Elbourne's), which is one of the most elegant and articulated E-type theories currently on the market (see Schlenker 2011c for a discussion of other E-type theories in the present context).

Each analysis involves some refinements, which we will only briefly mention.

- The dynamic analysis develops rules of semantic interpretation that allow he in (16) to depend on $a$ man without being in its scope. This formal connection is taken to be represented in language through

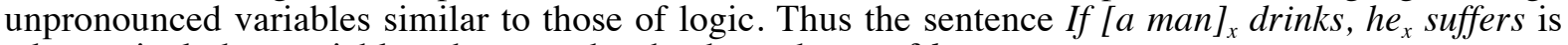
taken to include a variable $x$ that encodes the dependency of he on a man.

- The E-type analysis must address two challenges.

(i) First, it must explain which man the pronoun he (analyzed as meaning the man) refers to in (16) for there is certainly more than one man in the world. The standard solution is to take the word if to make reference to situations that are small enough to contain just one man. If a man drinks, he suffers is thus analyzed as: In every situation s in which a man drinks, the man in s suffers, with one man per situation.

(ii) Second, the E-type analysis must explain what kind of formal link connects he to $a$ man in (16). While the thrust of the approach is that this link is not directly interpreted (or else the analysis would be granting the main point of the dynamic solution), there appears to be some formal connection between the pronoun and its antecedent, which forces the latter to be a Noun Phrase. The motivation for this conclusion is that when one keeps the meaning of the if-clause constant, the presence of a Noun Phrase is still crucial to license the pronoun. For instance, John is married and John has a wife are usually synonymous; but although (18)a is grammatical, (18)b is not - it seems that the pronoun is missing a Noun Phrase as its antecedent.

(18) a. If John had a wife, he would be kind to her.

b. \#If John were married, he would be kind to her. 
This is known as the problem of the 'formal link' between the pronoun and its antecedent (Heim 1990). While different E-type theories give different solutions to this problem, we will follow here Elbourne's elegant analysis (Elbourne 2005): the desired data can be derived if her is represented as the wife, with ellipsis of wife, which must be recovered through a syntactic operation; ellipsis resolution can in effect establish the desired formal link between she and its antecedent.

In Schlenker 2011b,c, ASL and LSF data were used to suggest that:

(i) dynamic approaches predict the correct indexing patterns in the case of donkey sentences;

(ii) E-type approaches in general, and Elbourne's analysis in particular, are faced with a dilemma: either they are refuted by our sign language data, or they must be brought so close to dynamic semantics that they might end up becoming a variant of it.

To understand the nature of the dilemma, we must focus on so-called 'bishop' sentences, which are characterized by the fact that two pronouns are dependent on non-c-commanding indefinite antecedents with symmetric semantic roles, as in (19)a.

(19) a. If a bishop meets a bishop, he blesses him.

b. If [a bishop] ${ }_{x}$ meets [a bishop $]_{y}$, he $_{\mathrm{x}}$ blesses him $_{\mathrm{y}}$.

c. If [a bishop] meets [a bishop], he bishop blesses him bishop.

c'. If [a bishop] meets [a bishop], he bishop \#1 blesses him bishop \#2.

The 'bishop' sentence in (19)a is crucial because the situations referred to by the if-clause include two bishops that play symmetric roles (if a bishop x meets a bishop y, it is also true that a bishop y meets a bishop x).

- The dynamic analysis in (19)b has no difficulty here because each Noun Phrase introduces a separate variable; this allows each pronoun to depend on a different quantifier because $h e_{x}$ and $\operatorname{him}_{y}$ carry different variables (we could also have $h e_{y} / h_{i m}$, but not $h e_{x} / h m_{x}$ or $h e_{y} / h$ him $_{y}$ : the pronouns must carry different variables to refer to different bishops, or else the sentence would be understood as involving self-blessings - and in addition a reflexive would be needed).

- The E-type analysis must first postulate that the two bishops mentioned in the antecedent of (19)a are in principle distinguishable by some descriptions. This is not quite trivial: if bishop b meets bishop b', by virtue of the (symmetric) meaning of meet, it is also the case that bishop b' meets bishop b. In the theory developed in Elbourne 2005, the if-clause is taken to quantify over extremely fine-grained situations - so fine-grained, in fact, that a situation $<\mathrm{x}, \mathrm{y}$, meet $>$ in which $\mathrm{x}$ meets $\mathrm{y}$ is different from a situation $<\mathrm{y}, \mathrm{x}$, meet $>$ in which $\mathrm{y}$ meets $\mathrm{x}$. But this is not quite enough: to obtain the right meaning the pronouns must still be endowed with some additional material - perhaps provided by the context to pick out different bishops in a given case $\left\langle\right.$ bishop $_{1}$, bishop ${ }_{2}$, meet $>$. Even with the device of very fine-grained situations, (19)c is thus insufficient because it does not specify which bishop each pronoun refers to; in (19)c', the pronouns are enriched with the (stipulated) symbols \#1 vs. \#2, which are intended to pick out the 'first' or the 'second' bishop in $<$ bishop $_{1}$, bishop ${ }_{2}$, meet $>$. But the question is how these index-like objects end up in the Logical Form. For Elbourne's theory, the dilemma is as follows:

Horn I. If \#1 and \#2 are provided by a mechanism - possibly a contextual one - which is independent from Noun Phrase ellipsis resolution, we make the counterintuitive prediction that the two pronouns can be dependent on the same quantifier while still carrying different index-like objects. Importantly, this is so while we keep the intended meaning constant, a meaning that involves one bishop blessing the other bishop (no self-blessings here!). The reason for the counterintuitive prediction is that the role of distinguishing the two bishops falls on the symbols \#1 and \#2, which are provided independently of the ellipsis resolution process by which pronouns are formally linked to their antecedents. So long as ellipsis provides the right Noun Phrase (just bishop in (19)a), and no matter where this Noun Phrase is obtained, the right truth conditions will be produced.

Horn II. If \#1 and \#2 are inherited by the mechanism of ellipsis resolution itself, we will end up with something very close to a dynamic analysis: the antecedents carry a formal index, and the pronouns recover the very index carried by their antecedent, as is illustrated in (20):

(20) If [a bishop]\#1 meets [a bishop]\#2, he bishop \#1 blesses him bishop \#2.

The innovation of the analysis is in essence to add a story about ellipsis to a dynamic-style account, but it is not clear at all that the latter has been replaced with a classical account.

For spoken languages, one might well want to choose Horn I of the dilemma - after all, he and him in (19)a do not wear their antecedents on their sleeves, hence the counterintuitive prediction (namely that the two pronouns could go back to the same antecedent while still yielding the intended meaning) is just that, counterintuitive. But things are different in ASL (and LSF): in this case, there is 
clear evidence that the only way to obtain the intended reading is to ensure that the pronouns index different antecedents. This is shown in a structurally related example in (21). ${ }^{11}$

(21) WHEN [FRENCH MAN $]_{\mathrm{a}}$ a,b-MEET [FRENCH MAN $]_{\mathrm{b}}$,

'When a Frenchman meets a Frenchman,

a. IX-a WONDER WHO IX-b LIVE WITH.

the former wonders who the latter lives with.'

b. ? IX-b WONDER WHO IX-a LIVE WITH.

the latter wonders who the former lives with.'

c. \# IX-a WONDER WHO IX-a LIVE WITH.

the former wonders who the former lives with.'

d. \# IX-b WONDER WHO IX-b LIVE WITH.

the latter wonders who the latter lives with.'

(ASL, i P1040945)

Importantly, our sign language data do not refute all E-type analyses; in fact, it has been repeatedly argued in the literature that some E-type accounts are notational variants of dynamic accounts (Dekker 2004). But they suggest that there is overt motivation for the main ingredients of the dynamic analysis:

(i) A sign language locus appears to play very much the role of a formal index, which is carried by a pronoun and by the antecedent it is anaphoric to.

(ii) Just as is the case with loci, the formal relation which is mediated by dynamic indices is not constrained by c-command.

(iii) The semantics of indices and quantifiers guarantees that two indices introduced by different quantifiers can 'refer' (under an assignment function) to different individuals; the fact that two pronouns carry the same or different variables will thus have a direct semantic reflex, as is desired.

\section{$1.5 \quad$ Variables or features - or both $?^{12}$}

We take examples such as (5)-(7), as well as much of the foregoing discussion, to establish the plausibility of the Weak Hypothesis of Variable Visibility in 0a: an arbitrary number of loci may be associated to pronoun and to their antecedents to mark their dependency; furthermore, deictic pronouns referring to different objects may be associated with different loci. But this does not prove that loci share in all respects the behavior of logical variables, and thus these facts do not suffice to establish the Strong Hypothesis of Variability in $0 \mathrm{~b}$.

\subsubsection{Kuhn's objection}

This stronger hypothesis was recently attacked by Kuhn (to appear), who argues that loci should be seen as features akin to person and gender features, rather than as variables. On a positive level, Kuhn argues that the disambiguating effect of loci in (5)-(7) can be explained if loci are features that pronouns inherit from their antecedents, just as is the case of gender features in spoken languages (and it is uncontroversial that these are not variables). On a negative level, Kuhn argues that treating loci as variables predicts that they should obey two constraints that are in fact refuted by his ASL data.

- First, a logical variable is constrained to depend on the structurally closest operator it is co-indexed with. Thus in standard logics the boxed variable $x_{l}$ in (22)a cannot be semantically dependent on the universal quantifier $\forall x_{1}$ because of the intervening quantifier $\exists x_{1}$-by contrast with (22)b, where the intervening quantifier carries a different index. For the same reason, the boxed variable in both formulas cannot be free and refer (deictically, in linguistic parlance) to a fixed individual.

(22) Variable capture in First-Order Logic

$\mathrm{X}_{1}$ can be bound by $\forall \mathrm{x}_{1}$ in $\mathrm{b}$. but not in $\mathrm{a}$.

a. $\forall \mathrm{x}_{1} \exists \mathrm{x}_{1} \ldots \mathrm{P} \mathrm{X}_{1} \ldots$

b. $\forall \mathrm{x}_{1} \exists \mathrm{x}_{2} \ldots \mathrm{P} \mathrm{x}_{1} \ldots$

Briefly, Kuhn (to appear) argues that the natural language version of this prediction is falsified by the ASL sentence in (23). Without getting into details of implementation, what matters for our purposes is that despite the fact that the two possessives POSS-b and POSS-b index the same locus $b$, the

11 (21) is a bit more complex than (19)a because we wanted to display a sentence that does not involve a 'Condition B' configuration in which the second pronoun is locally c-commanded by the first; in the end this point is immaterial, since in any event the intended reading does not involve coreference between the two pronouns, and hence shouldn't yield a Condition B effect in the first place.

${ }^{12}$ This section borrows from Schlenker 2014b. 
sentence is 4-way ambiguous, with a meaning akin to: Jessica told me that only Billy is an $x$ such that $x /$ Billy told me $x /$ Billy's favorite color, with two interpretive choices for the boxed and for the underlined pronoun. He argues that this ambiguity cannot be derived if loci really are variables because $P O S S-b \mid$ and $P O S S-b$ should depend on the same operator and thus have the same value (both corresponding to $x$, or both corresponding to Billy), which excludes two of the readings.

\section{(23) 7 IX-a JESSICA TOLD-ME IX-b BILLY ONLY-ONE FINISH-TELL POSS-b MOTHER} POSS-b FAVORITE COLOR.

'Jessica told me that only Billy told his mother his favorite color.'

Can be read as: bound-bound, bound-free, free-bound, or free-free. (Kuhn, to appear)

- Second, in standard logics the two occurrences of the variable $x_{I}$ in (24) must have the same semantic value - in particular, if no quantifier binding $x_{1}$ appears at the beginning of the formula, both occurrences will be free and will denote a fixed individual.

\section{(24) Variable re-use in First-Order Logic}

The two occurrences of $x_{l}$ must denote the same object. ... $\mathrm{Px}_{1} \& \mathrm{Qx}_{1} \ldots$

Kuhn refutes this prediction by showing that in (25) a single locus is assigned to John and Mary, and another locus is assigned to Bill and Suzy. As a result, the boxed occurrences $\overline{I X-a}$ and $\mid I X-b$ refer to John and Mary respectively, while the underlined pronouns $\underline{I X-a}$ and $\underline{I X-b}$ refer to Mary and Suzy.

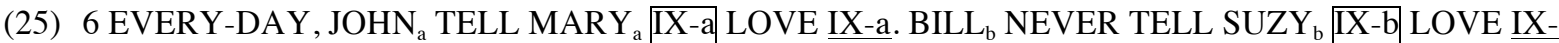
b. 'Every day, John $_{\mathrm{i}}$ tells Mary ${ }_{\mathrm{j}}$ that he ${ }_{\mathrm{i}}$ loves her $_{\mathrm{j}}$. Bill $\mathrm{k}_{\mathrm{k}}$ never tells Suzy $\mathrm{S}_{1}$ that he $\mathrm{k}_{\mathrm{k}}$ loves her $_{1}$ ' (ASL, Kuhn, to appear)

\subsubsection{Two directions}

- Kuhn solves these problems by treating loci as features which are not interpreted, but are inherited by a mechanisms of morpho-syntactic agreement; this allows him to provide a 'variable-free' treatment of loci (although he does not claim that his data require it, only that they make it possible).

To see the appeal of this treatment of loci as features, consider the behavior of the feminine features of her in (26) and of the second person features of your in (27).

(26) In my study group,

a. Mary did her homework (but John didn't do his).

b. only Mary did her homework (... therefore John didn't do his).

c. only Mary $\lambda \mathrm{i}^{\mathrm{fem}} \mathrm{t}_{\mathrm{i}}$ did her $\mathrm{r}_{\mathrm{i}}$ homework

(27) In my study group,

a. You did your homework (but John didn't do his).

b. only you did your homework (... therefore others didn't do theirs).

$\mathrm{b}^{\prime}$. only you $\lambda \mathrm{i}^{\text {2nd }} \mathrm{t}_{\mathrm{i}}^{\text {2nd }} \mathrm{did}$ your $\mathrm{i}$ homework

In the simple examples in (26)a and (27)a, these features constrain the denotation of the possessive pronoun, which may only denote female individuals in (26)a, and only the speaker in (27)a. But something interesting happens in (26)b and (27)b: due to the semantics of only, the possessive pronoun can be interpreted as a bound variable which ranges over non-female individuals and over non-addressees. This has lead several researchers (e.g. Heim 1991, 2008, Kratzer 2009, Schlenker 1999, 2003, Stechow 2004) to posit that in this case these features remain uninterpreted; in some frameworks this is represented in the Logical Forms in (26)c-(27)c by including the features on the variables, but in barred form to indicate that they can be 'deleted under agreement' with their binder.

If features can be inherited without being interpreted in such cases, why couldn't one extend the same mechanism to ASL loci so as to account for Kuhn's cases of 'variable capture'? If so, it could be that these are just features, which constrain antecedence relations but are not otherwise interpreted. Kuhn must accept the consequence that features need not be part of a closed inventory, since as mentioned at the outset there is no natural upper bound on the number of loci that can appear in a sentence. Be that as it may, Kuhn's analysis has the further advantage of explaining why the same locus can be used to refer to distinct individuals in the case of 'locus re-use' in (25). For him, this case is no different from that of ambiguous uses of the pronoun she, which may refer to different individuals as long as they are female: features may but need not disambiguate reference.

- So in view of Kuhn's objections, can we still preserve the view that loci are sometimes overt variables? A positive answer is sketched in Schlenker 2014b, which suggests that loci may both display the behavior of variables and of features - they are thus 'featural variables'. Specifically, when 
they are interpreted their semantics is given by an assignment function, just like that of standard indices. But they may be disregarded in precisely the environments in which person or gender features can be disregarded. Furthermore, in many environments loci constrain the value of covert variables. Without getting into details of implementation that are developed elsewhere (Schlenker 2014b), it will suffice for present purposes to mention a formal analogy between $2^{\text {nd }}$ person features in standard theories and loci in the present analysis.

-In standard theories, a $2^{\text {nd }}$ person feature is evaluated with respect to the context of evaluation, and it constrains pronouns that carry it to refer to the speaker of that context; formally, we can write that with respect to a context $\mathrm{c}$ and an assignment function $\mathrm{s}$, an expression $E^{2 n d}$ carrying a $2^{\text {nd }}$ person feature only gets a semantic value if its denotation $[[\mathrm{E}]]^{\mathrm{c}, \mathrm{s}}$ is the addressee of $\mathrm{c}$, which we can write as $\mathrm{c}(2)$.

-By analogy, we can say that an expression $E^{a}$ carrying a locus $a$ only gets a semantic value if its denotation $[[\mathrm{E}]]^{\mathrm{c}, \mathrm{s}}$ is the value of locus $a$, i.e. s(a). Thus $2^{\text {nd }}$ person features and loci alike are interpreted relative to a parameter of the interpretation function - the context parameter in the first case, the assignment function in the second. Furthermore, both display a peculiar behavior in some environments, in the sense that under some conditions they may remain uninterpreted under only and in the course of ellipsis resolution.

In the end, then, one may view loci as non-standard features (which may be created 'on the fly' out of an open inventory), or as 'featural variables' which are interpreted in some cases and but not in others. The debate between the two approaches remains open - and it might well be that the two sides will converge when all the relevant data are considered.

\section{Loci as Pictures ${ }^{13}$}

In the cases we have discussed up to this point, sign language makes some aspects of the Logical Forms of sentences more transparent than they are in spoken language, for accidental or sometimes for essential reasons (notably, the fact that indices are overtly realized in sign language but not in spoken language). In this section, we turn to cases in which sign language pronouns have greater expressive resources than their spoken language counterparts due to the availability of rich iconic mechanisms in sign language.

\section{$2.1 \quad$ Iconic effects}

To see an intuitively clear example of an iconic effect, consider the verb GROW in (28), which can be realized in a variety of ways, six of which were tested in (29); in the 'slow movement' row, we have included pictures of the beginning and endpoint of GROW.

(28) POSS-1 GROUP GROW.

'My group has been growing.' (ASL; 8, 263)

(29) Representation of GROW

\begin{tabular}{|l|l|l|l|}
\hline & Narrow endpoints & Medium endpoints & Broad endpoints \\
\hline Slow movement & small amount, slowly & medium amount, slowly & large amount, slowly \\
& &
\end{tabular}

As seen in (29), the sign for GROW starts out with the two hands forming a sphere, with the closed fist of the right hand inside the hemisphere formed by the left hand; the two fists then move away from each other on a horizontal plane (simultaneously, the configuration of the right hand changes from closed to open position). The signer varied two main parameters in (29): the distance between

${ }^{13}$ This section borrows from Schlenker $2013 b$ and Schlenker 2015a, which in turn summarize results that appeared in Schlenker et al. 2013. 
the endpoints; and the speed with which they were reached (only the first parameter is depicted). All variants were acceptable, but yielded different meanings. Intuitively, there was a mapping between the physical properties of the sign and the event denoted: the broader the endpoints, the larger the final size of the group; the more rapid the movement, the quicker the growth process.

Such effects are pervasive in sign language. Schlenker et al. 2013 asked (i) how they interact with the representation and interpretation of variables; and (ii) how this interaction should be modeled. Their main claim was that sign language loci are simultaneously variables and pictorial representations: their values are provided by assignment functions, but the interpretation function in general and the assignment function in particular are constrained to preserve some geometric properties of signs, and thus they have an iconic component. In effect, this proposal attempted to reconcile two camps in sign language research. The 'formalist camp' (e.g. Lillo-Martin and Klima 1990, Neidle et al. 2000, Sandler and Lillo-Martin 2006) emphasizes the importance of predictive formal models, but traditionally it had relatively little to say about iconic considerations. The 'iconic camp' (e.g. Cuxac 1999, Taub 2001, Liddell 2003) emphasizes the importance of iconic conditions, but does so within frameworks that are considered insufficiently explicit by the formalist side. Schlenker et al. 2013 claimed that insights of the iconic camp are essential for a proper understanding of the semantics of sign language variables; but this understanding requires the kind of formal frameworks espoused by formalists - hence the necessity to incorporate to the latter an explicit iconic component.

We will argue below that sign language loci can play the role of iconic variables, i.e. of symbolic expressions that are both logical variables and simplified pictures of what they denote. We make our case on the basis of three phenomena: (i) plural loci, where relations of inclusion and complementation among loci are directly reflected in their denotations (Section 2.2); (ii) structured singular loci, where different agreement verbs target different parts of a locus, analyzed as a structured area rather than as a point in signing space (Section 2.3); and (iii) high loci, which may be used to refer to tall, important or powerful individuals (as well as low loci; Section 2.4).

\subsection{Embedded Loci: Plurals ${ }^{14}$}

The simplest instance of an iconic constraint concerns plural ASL and LSF loci, which are usually realized as (semi-)circular areas. In special contexts these can be embedded within each other, and we hypothesize that this gives rise to cases of structural iconicity, whereby topological relations of inclusion and relative complementation in signing space are mapped into mereological analogues in the space of loci denotations (see Emmorey 2014 for a broader discussion).

Our initial focus is on the anaphoric possibilities made available in English by the sentence Most students came to class. Recent research has argued that such a sentence makes available two discourse referents for further anaphoric uptake: one corresponding to the maximal set of students, as illustrated in (30)b ('maximal set anaphora'); and one for the entire set of students, as illustrated in (30)c ('restrictor set anaphora').

(30) a. Complement set anaphora: \#Most students came to class. They stayed home instead.

b. Maximal set anaphora: Most students came to class, and they asked good questions.

c. Restrictor set anaphora: Most students came to class. They are a serious group.

Crucially, however, no discourse referent is made available for the set of students that didn't come to class ('complement set anaphora', as this is the complement of the maximal set within the restrictor set); this is what explains the deviance of (30)a (see Nouwen 2003 and Schlenker et al. 2013 for further discussion of apparent counterexamples).

On the basis of ASL and LSF data, Schlenker et al. 2013 made two main observations.

Observation I. When a default plural locus is used in ASL, data similar to (30) can be replicated e.g. complement set anaphora with most is quite degraded. This is illustrated in (31), with average judgments (per trial) on a 7-point scale, with a total of 5 trials and 3 informants.

(31) POSS-1 STUDENT FEW a-CAME CLASS.

3.6 IX-arc-a a-STAY HOME

POSS-1 STUDENT MOST a-CAME CLASS.

Intended: 'Few/Most of my students came to class. They [the students that didn't come] stayed home.'

Observation II. When embedded loci are used, the effect is circumvented: one large locus (written as $a b$, but signed as a single circular locus) denotes the set of all students; a sub-locus $(=a)$ denotes the set of students who came; and a complement locus $(=b)$ thereby becomes available, denoting the set of students who didn't come, as illustrated in (32) and (33).

${ }^{14}$ This section borrows from Schlenker 2013b and Schlenker et al. 2013. 
(32) POSS-1 STUDENT IX-arc-ab MOST IX-arc-a a-CAME CLASS.

'Most of my students came to class.'

a. 7 IX-arc-b b-STAY HOME

'They stayed home.'

b. 7 IX-arc-a a-ASK-1 GOOD QUESTION

'They asked me good questions.'

c. 7 IX-arc-ab SERIOUS CLASS.

'They are a serious class.'

(ASL; 8, 196)

(33)

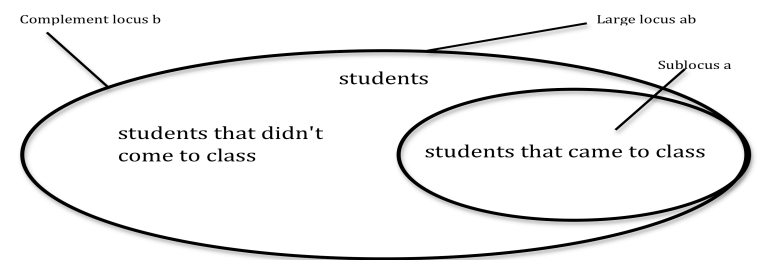

Schlenker et al. 2013 account for Observation I and Observation II by assuming that (i) Nouwen is right that in English, as well as ASL and LSF, the grammar fails to make available a discourse referent for the complement set, i.e. the set of students who didn't come; but (ii) the mapping between plural loci and mereological sums preserves relations of inclusion and complementation, which in (32)a makes available the locus $b$.

The main assumptions are that (a) the set of loci is closed with respect to relative complementation: if $a$ is a sublocus of $b$, then $(b-a)$ is a locus as well; and (b) assignment functions are constrained to respect inclusion and relative complementation: if $a$ is a sublocus of $b$, the denotation of $a$ is a subpart of the denotation of $b$, and $(b-a)$ denotes the expected complement set. These conditions are stated more completely in (34):

(34) Conditions of loci

Let LOC be the set of plural loci that appear in signing space, and let $\mathrm{s}$ an admissible assignment function that assigns values to loci. We make the assumptions in (a)-(b), where we view plural loci as sets of geometric points, and loci denotations as sets of individuals.

a. Conditions on LOC: for all $\mathrm{a}, \mathrm{b} \in \mathrm{LOC}$, (i) $\mathrm{a} \subseteq \mathrm{b}$ or $\mathrm{b} \subseteq$ a or $\mathrm{a} \cap \mathrm{b}=\varnothing$; (ii) if $\mathrm{a} \subset \mathrm{b}$, (b-a) $\in \mathrm{LOC}$

b. Conditions on s: for all $\mathrm{a}, \mathrm{b} \in \mathrm{LOC}$, (i) $\mathrm{a} \subset \mathrm{b}$ iff $\mathrm{s}(\mathrm{a}) \subset \mathrm{s}(\mathrm{b})$; (ii) if $\mathrm{a} \subset \mathrm{b}, \mathrm{s}(\mathrm{b}-\mathrm{a})=\mathrm{s}(\mathrm{b})-\mathrm{s}(\mathrm{a})$

In (32)a, where embedded loci are used, we can make the following reasoning:

- Since $a$ is a proper sublocus of a large locus $a b$, we can infer by (34)a(ii) that $(a b-a)$ (i.e. $b)$ is a locus as well;

- by (34)b(i), we can infer that $s(a) \subset s(a b)$;

- and by (34)b(ii), we can infer that $s(b)=s(a b)-s(a)$.

In this way, complement set anaphora becomes available because ASL can rely on an iconic property which is inapplicable in English. But this does not mean that there is a proper grammatical (non-iconic) difference between these two languages: as we saw, with default loci the English data are replicated, which suggests that Nouwen's assumption that the grammar does not make available a discourse referent for the complement set applies to ASL just as it does to English. Rather, it is because of iconic conditions on plural loci, not grammar in a narrow sense, that a difference does arise in the case of embedded loci. ${ }^{15}$

\subsection{Structured singular loci: agreement verbs}

Agreement verbs are realized as movements that target one or several loci corresponding to their arguments. For instance, in LSF 1-TELL-2 'I tell you' is realized as movement starting in the locus denoting the signer and ending in the locus denoting the addressee. Now despite many disagreements,

\footnotetext{
${ }^{15}$ One additional remark should be made in connection with our discussion of the debate between the analyses of loci as variables vs. as features (in Section 1.5). It is notable that the locus $b$ in (32)a and (33) is not inherited by way of agreement, since it is not introduced by anything. From the present perspective, the existence of this locus is inferred by a closure condition on the set of loci, and its interpretation is inferred by an iconic rule. But the latter makes crucial reference to the fact that loci have denotations. It is not trivial to see how this result could be replicated in a variable-free analysis in which loci don't have a denotation to begin with. Presumably, the complement set locus would have to be treated as being deictic (which is the one case in which the variablefree analysis has an analogue of variable denotations). This might force a view in which complement set loci are handled in a diagrammatic-like fashion, with co-speech gestures incorporated into signs - a point to which we briefly return in the conclusion.
} 
Liddell 2003 and Lillo-Martin and Meier 2011 agree that the effects of iconicity are felt with agreement verbs, which target different parts of a locus depending on their meaning - e.g. Liddell 2003 writes for instance that 'ASK-QUESTION ${ }^{y}$ is directed toward the chin/neck area' of a locus, while 'COMMUNICATE-TELEPATHICALLY-1 $1^{[\mathrm{RECIP}] .}$... is directed toward the forehead'.

On an empirical level, Schlenker 2011b and Schlenker et al. 2013 showed that (i) Liddell's claims also hold of donkey and bound pronouns, and that (ii) the particular part of a locus which is targeted by agreement sometimes depends on the position (upright or hanging) of the person referred to (data in this latter respect are complex, and we can only scratch their surface here).

Let us consider first the issue of height differences across agreement verbs in LSF (ASL facts are similar, but the influence of body position seems to be a bit more subtle than in LSF). In (35), we contrast the agreement verbs 'communicate by telepathy' and 'exchange thoughts' with respect to the heights that they target: the former preferably targets a high locus; the latter an intermediate locus; ratings are averages per trial over two informants.

(35) YESTERDAY LINGUIST ${ }_{\mathrm{b}}$ PHILOSOPHER $_{\mathrm{a}} \mathrm{b}, \mathrm{a}-\mathrm{MEET}$.

1. b,a-EXCHANGE 2. b,a-TELEPATHY

'Yesterday, a linguist and a philosopher met. They 1 . exchanged thoughts 2 . communicated by

telepathy.' (LSF, 19, 68)

$\begin{array}{ll}\text { a. High locus (1) } 2 \mathrm{~b}^{\text {high }}, \mathrm{a}^{\text {high }} \text {-EXCHANGE } & \text { (2) } 6.4 \mathrm{~b}^{\text {high }}, \mathrm{a}^{\text {high }} \text { - TELEPATHY }\end{array}$

b. Intermediate locus (1) $6.4 \mathrm{~b}^{\text {medium }}, \mathrm{a}^{\text {medium }}$-EXCHANGE (2) $3 \mathrm{~b}^{\text {medium }}, \mathrm{a}^{\text {medium }}$-TELEPATHY

c. Low locus (1) $1.2 \mathrm{~b}^{\text {low }}, \mathrm{a}^{\text {low }}$-EXCHANGE (2) $1 \mathrm{~b}^{\text {low }}, \mathrm{a}^{\text {low }}-$ TELEPATHY

Turning to the second observation: in (37), a situation was described in which several individuals were either hanging from a branch or standing on a branch. In both cases, a horizontal movement of one hand represented the branch, while a vertical classifier represented the position of the body - with opposite orientations in the two conditions. The signer sought to ensure that the vertical space occupied by the ('hanging' or 'standing') person classifier was the same in the 'hanging' and in the 'standing' position, as is schematically represented in (36).

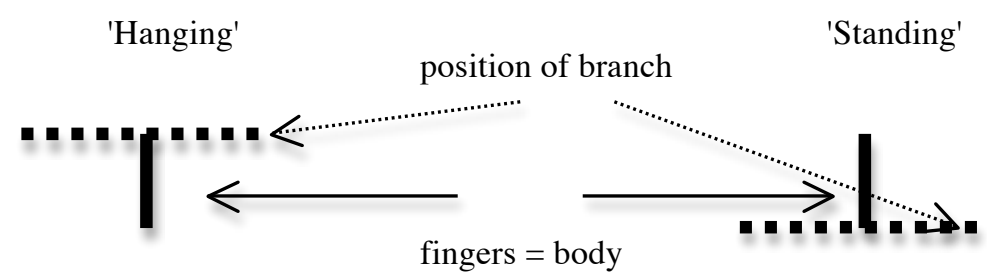
TREE BRANCH FRIEND POSS-1 SEVERAL
IX-a WANT IX-1 1-ASK-a wanted me to ask him questions.' (LSF, 20, 9)
a. High locus: 1-ASK-a high $^{\text {his }}$
(1) 2
(2) 5.5
b. Intermediate locus: 1-ASK-amedium
(1) $6.5 \quad$ (2) 3
c. Low locus: 1-ASK-a $a^{\text {high } / \text { medium/low }}$ (1) 2.5
(2) 1

(1) HANG-rep (2) STAND-rep

'Several of my friends were (1) hanging from (2) standing on a tree branch. One of them told me he

For each condition, there were three target heights that were tested for the agreement verb ASK: high, intermediate and low. As can be seen, the high locus is relatively acceptable in the 'standing' but not in the 'hanging' condition; for the intermediate locus, we obtain the opposite pattern. Thus the body position (standing or upside down) influences the choice of the point targeted by agreement verbs: there is a reversal of preferences across the two conditions.

A more direct argument for reversal is afforded by the sentence in (38): two agreement verbs targeting different heights, TELEPATHY ('communicate by telepathy' - high target in the 'standing' condition) and EXCHANGE ('exchange ideas' - intermediate target in the 'standing condition') appear in the same sentence, and three conditions were contrasted, with TELEPATHY targeting (a) a higher height than, or (b) the same height as, or (c) a lower height than EXCHANGE. Strikingly, in the 'hanging' condition in (38)1., (c) was preferred to (a)-(b); whereas in the standard control condition in 2. (involving a 'sitting' rather than 'standing' position, as in our earlier examples), (a) was preferred to (b)-(c).

YESTERDAY TREE BRANCH CLLINGUIST CLPHILOSOPHER. neg a,b-EXCHANGE a,b- TELEPATHY

'Yesterday a linguist and a philosopher were hanging from / standing on a branch. They exchanged ideas but did not communicate by telepathy.'

1. 'Hanging': $=$ hanging $(\mathrm{LSF}, 23,15)$ 


\author{
(a) 2 TELEPATHY > EXCHANGE (b) 3.5 TELEPATHY = EXCHANGE (c) 6 TELEPATHY < \\ EXCHANGE \\ 2. 'Standing': ___ = standing $(\mathrm{LSF}, 23,14)$ \\ (a) 6 TELEPATHY $>$ EXCHANGE (b) 3.5 TELEPATHY = EXCHANGE (c) 2 TELEPATHY < \\ EXCHANGE
}

Schlenker et al. 2013 posited a presuppositional semantics for agreement verbs, but they endowed it with an explicit iconic requirement (in the cases we discuss here, these happen to hold both of the subject and of the object argument). To state it, we need to distinguish between area loci, which are structured (with a head and a foot) and receive a denotation from an assignment function; and point loci, which are parts of area loci that are targeted by agreement verbs. Now the iconic requirement makes crucial reference to the 'relative height' of a point locus within an area locus, measured from the foot of the area locus, as is illustrated in (39). The idea is that in the 'standing' condition, the verb TELEPATHY targets a higher point locus of the area locus than the verb EXCHANGE - i.e. a point which is closer to the top of the area locus. But for this reason, when an area locus is upside down because it denotes a person in hanging position (see (39)), the pattern is reversed, and TELEPATHY targets a lower point locus than EXCHANGE.

(39) Constant relative height $\mathrm{h}$ of a point locus i relative to an area locus I despite changes of orientation ( represents the 'head' position of the area locus; the opposite end is the foot position)

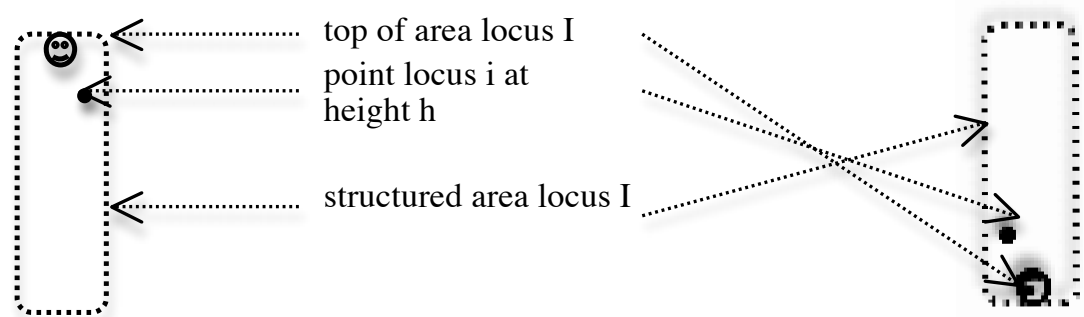

Without getting into formal details (discussed in Schlenker et al. 2013), we can informally state the desired result. The agreement construction $i$-ASK-QUESTIONS- $j$ is realized as a movement from a point $i$ of an area locus $I$ to a point $j$ of an area locus $J$; a presupposition failure is obtained unless $i$ is with respect to $I$ at the same relative height as the chin of $\mathrm{s}(\mathrm{I})$ with respect to the body of $\mathrm{s}(\mathrm{I})$; and similarly for $j, J$. In this way, we obtain a presupposition that the agreement verb targets positions that correspond to those of the chins of the relevant individuals, in keeping with the empirical observations of Liddell 2003, but stated within a model-theoretic framework in which iconic conditions can interact with standard logical operators.

\title{
2.4 High and low loci
}

Under restricted conditions, loci can be introduced high or low in signing space to refer to entities that are tall/powerful/important, or short. Importantly, the relevant inferences are preserved with pronouns embedded under negation; for this reason, we treat these inferences as presuppositions as well. An ASL example is given in (40):

(40) YESTERDAY IX-1 SEE R [= body-anchored proper name]. IX-1 NOT UNDERSTAND IX-a ${ }^{\text {high } / \text { normal/ }}$

Inferences: high locus $-\mathrm{R}$ is tall, or powerful/important; normal locus: nothing special; low locus: $\mathrm{R}$ is short

In Schlenker et al. 2013, height specifications were taken to have the same kind of presuppositional semantics as gender features (Cooper 1983), but with an iconic component, as seen in (41), which only covers the 'tall' vs. 'short' implications of high or low loci (the crucial presupposition is in bold).

(41) Presuppositions introduced by high loci

Let $\mathrm{c}$ be a context of speech, $\mathrm{s}$ an assignment function and $\mathrm{w}$ a world ( $\mathrm{c}_{\mathrm{w}}=$ world of $\left.\mathrm{c}\right)$. If $i$ is a locus, $n$ is a locus with neutral height, $h$ is a measure of the heights of loci in signing space, $h_{c}\left(c_{w}\right)$ is a measure of height denotations in $\mathrm{c}_{\mathrm{w}}$ given by the context $\mathrm{c}$, and $\alpha_{\mathrm{c}}>0$ is a parameter given by the context $\mathrm{c}$. Then: $[[I X-i]]^{c, s, w}=\#$ iff $s(i)=\#$ or li $-\mathbf{n l} \neq \mathbf{0}$ and $\mathbf{h}_{\mathbf{c}}\left(\mathbf{c}_{\mathrm{w}}\right)(\mathbf{s}(\mathbf{i}))-\mathbf{h}_{\mathbf{c}}\left(\mathbf{c}_{\mathrm{w}}\right)(\mathbf{s}(\mathbf{n})) \neq \boldsymbol{\alpha}_{\mathbf{c}}(\mathbf{h}(\mathbf{i})-\mathbf{h}(\mathbf{n}))$. If $[[I X-i]]^{\mathrm{c}, \mathrm{s}, \mathrm{w}} \neq \#$, $[[\mathrm{IX}-\mathrm{i}]]^{\mathrm{c}, \mathrm{s}, \mathrm{w}}=\mathrm{s}(\mathrm{i})$. 
In words: the part in bold introduces a presupposition that the difference in height between the loci i and a locus of neutral height $\mathrm{n}$ should be proportional to the difference in height of their denotions, modulo a multiplicative parameter $\alpha_{\mathrm{c}}$ given by the context c. ${ }^{16}$

Now it would in principle be possible to state a version of (41) that does not make reference to a geometric projection between the signing space and the world of the context; this would in particular be the case if our initial and informal characterization of the import of high loci were fully correct. But things turn out to be more subtle: even if the denoted person is tall, one might still have to use a normal or even a low locus if that person is in lying rather than in standing position. This is shown for ASL in (42), where three pronominal heights are tested in three separate conditions, involving a person in (a) standing, (b) sitting, or (c) lying position.

(42) Context: People seek self-knowledge in the weirdest of situations.

\section{YESTERDAY VERY TALL PHILOSOPHER PERSON}



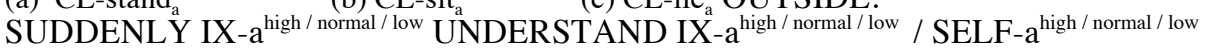

'Yesterday a very tall philosopher was (a) standing (b) sitting (c) lying in the park. Suddenly he understood him / himself.' (ASL, 10, 110, 111 and 112; see Schlenker et al. 2013 for detailed ratings for all conditions.) Two pronouns were contrasted, the non-reflexive pronoun $I X-a$ and the reflexive pronoun SELF- $a$. Both targeted three different heights: high, normal, low, as illustrated in (43)

(43) Rough position of the index and middle finger of the dominant hand and of the non-dominant hand in examples (42)

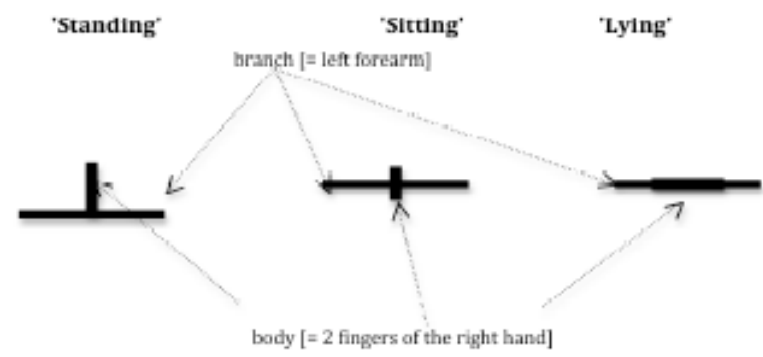

In all cases, the pronoun $I X-a$ was clearly dispreferred, as this is a configuration of local binding which requires a reflexive pronoun; this highlights the fact that SELF- $a$ is a bona fide reflexive pronoun, whose syntactic behavior is reminiscent of its counterparts of spoken language (see Koulidobrova 2011 for a detailed discussion). Within the SELF- $a$ examples, high loci were possible in the 'standing' condition, less so in the 'sitting' condition, and degraded in the 'lying' condition. In other words, SELF-a behaves in this case as a bona fide reflexive, but one that also has a strong iconic component: it is an 'iconic reflexive'.

\section{$2.5 \quad$ Further developments}

Several questions were addressed in more recent research.

(i) First, how rich is the iconic semantics that is required for the analysis of pronouns? In the semantics we gave in (41), only the vertical height of loci plays a role. But the structured loci we saw at work with agreement verbs in Section 2.3 already suggest that a richer pictorial component may sometimes be needed. Furthermore, even outside the domain of agreement verbs, Schlenker 2014a considers cases of rotation in which one needs to posit that loci are areas of space rather than points, and that they are simplified pictures of what they denote. In effect, one needs incorporate into sign

\footnotetext{
${ }^{16}$ Importantly, the height of denotations is assessed relative to the world $\mathrm{c}_{\mathrm{w}}$ of the context: the presupposition is in that sense indexical. This also seems to be the case of the presupposition triggered by she in English: in (i), the gender features of she can only interpreted de re, i.e. with respect to the context of the speech act rather than with respect to the world of evaluation.

(i) Bill wore a dress and make-up and John didn't realize that he was a man. He said that he/\#she looked great and that he/\#she was staring at him. (Sharvit 2008)

The indexical character of height specifications can be tested in ASL: in (ii)a and (ii)b, the height presupposition triggered by $I X-b^{\text {high }}$ is satisfied with respect to my cousin's beliefs, but only in (ii)b is it satisfied with respect to the world $c_{w}$ of the context $c$. For this reason, only (ii)b is fully acceptable for our informant.
}

(ii) POSS-1 COUSIN IX-a (a) 3 WRONGLY THINK / (b) 7 KNOW POSS-1 YOUNG BROTHER TALL. IX-a THINK IX-b ${ }^{\text {high }}$ BASKETBALL PERSON.

'My cousin (a) wrongly thinks (b) knows that my younger brother is tall. He thinks he is a basketaball player.' (ASL, 10, 60) 
language semantics a kind of 'pictorial semantics', recently investigated in a very different context by Greenberg 2012.

In Schlenker 2014a, the argument was based on ASL and LSF paradigms involving a short and a tall person training to be astronauts by being rotated in various positions. It will help to start from the diagram in (44)a, which displays two finger classifiers, one representing a tall astronaut (on the right) and the other representing a short astronaut (on the left). Four sentences were constructed in which the classifiers were rotated in four different ways, as seen in (44)b.

(44) Tall vs. short person rotations - schematic representation from the signer's perspective a. Two finger classifiers

b. 4 positions of the finger classifiers (in 4 sentences)

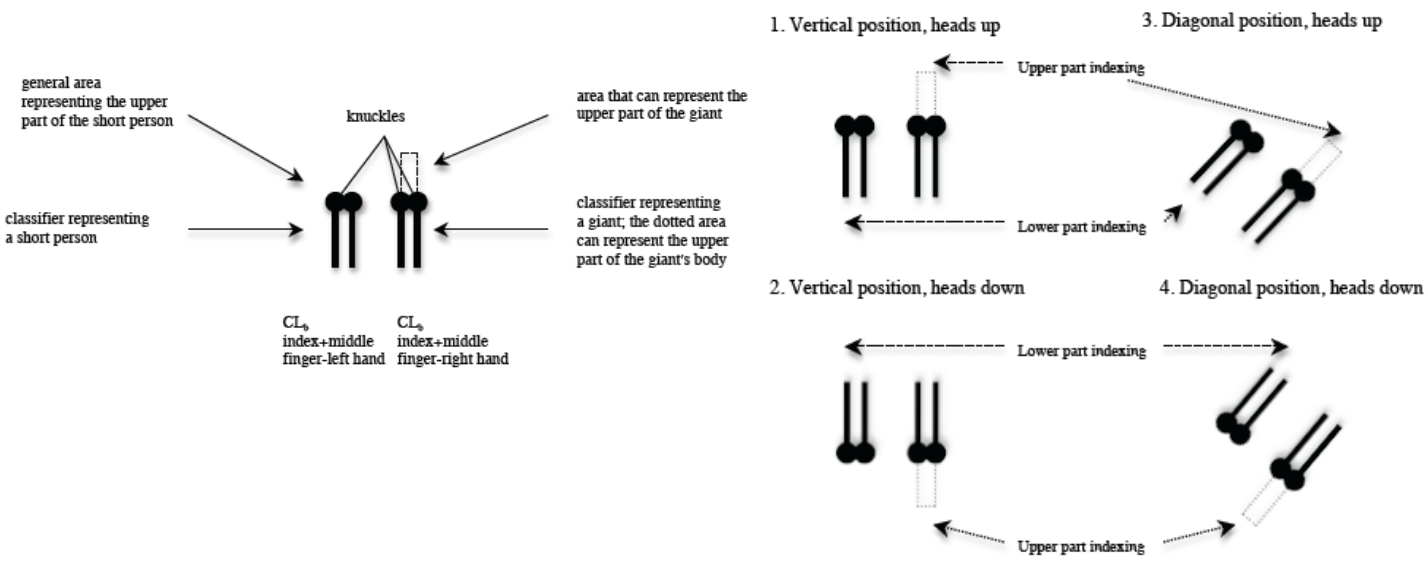

Our initial goal was to show that (i) in 'standing' position, 'tall person' indexing could be higher than 'short person' indexing - as is expected given the discussion in Section 2.4; but in addition, that (ii) the indexed position could rotate in accordance with the position of the denoted person on the assumption that there was a geometric projection between the structured locus and the denoted situation. Accordingly, we considered the discourse in (45), which makes reference to a tall and to a short individual, and explains that they were rotated as shown in (44). As represented in (44), $C L_{a}$ and $C L_{b}$ are finger classifiers representing a tall and a short person respectively.

(45) HAVE TWO ROCKET PERSON [ONE HEIGHT $]_{\mathrm{a}}[\mathrm{ONE} \text { SHORT }]_{\mathrm{b}}$. THE-TWO-a,b PRACTICE DIFFERENT VARIOUS-POSITIONS [positions shown].

IX-a HEIGHT IX-b SHORT, $\mathbf{C L}_{\mathbf{a}}$-[position]-CL $\mathbf{L}_{\mathbf{b}}$-[position].

'There were two astronauts, one $\mathrm{a}_{\mathrm{a}}$ tall, one $\mathrm{e}_{\mathrm{b}}$ short. They trained in various positions [various positions shown]. They were in position _ [ [1 position shown].

a. IX-a_upper_part LIKE SELF-a_upper_part.IX-b_lower_part NOT.

The tall one liked himself. The short one didn't.'

b. *IX-a_upper_part LIKE SELF-a_upper_part. IX-b_lower_part NOT LIKE SELF-b_upper_part. [intended:] The tall one liked himself. The short one didn't like himself.'

(ASL; 17, 178, 179, 180, and 181)

Let us concentrate for the moment on the boxed part of (45)a. In the 'vertical position, heads up' depicted in (44)b1, the reflexive $S E L F$-a_upper_part targeted a position above the knuckles because the classifier $C L_{a}$ denoted a tall person. But as different cases of rotation were considered, the finger classifiers rotated accordingly, and the 'upper part' of the locus indexed by SELF-a_upper_part did as well, as depicted in (44)b2, b3, b4.

(iii) In a second step, one could ask how integrated to the grammatical system height specifications are. We mentioned in our discussion of (41) that their semantics was modeled after that of gender features, albeit with an iconic twist (Schlenker et al. 2013). Schlenker 2014a cautiously suggests that height specifications resemble gender features in another respect: they can somehow be disregarded under ellipsis. An example is given in (46)a, where the elided VP has a bound reading, unlike its overt counterpart in (46)b. On the (standard) assumption that VP ellipsis is effected by copying part the antecedent VP, this suggests that the feminine features of that antecedent can be ignored by ellipsis resolution, as represented with a barred pronoun in (46)b (as was the case in (26)b above)/

(46) In my study group,

a. Mary did her homework, and John did too. 
=> can imply: John did his homework too.

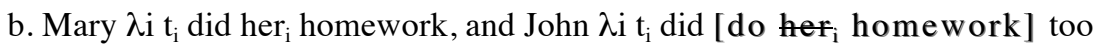

By a similar logic, the unboxed part of (45)a was designed to test whether ASL ellipsis makes it possible to disregard height specifications. Here the antecedent VP includes a reflexive pronoun indexing the upper part of a locus, which is adequate to refer to a tall but not to a short person. Despite this apparent mismatch, the elided sentence is acceptable - unlike the overt counterpart in (45)b, which includes a reflexive SELF referring to a short person but with high specifications. Thus in ASL height specifications can be ignored by the mechanism that computes ellipsis resolution, just as is the case for gender features in (46).

The interpretation of these results requires considerable care, however. The main question is whether apparent 'disappearance' under ellipsis is a behavior that characterizes features only, or holds true of a broader class of expressions. Schlenker 2014a didn't give a final answer, and it is argued in Schlenker 2015b,c that co-speech gestures in spoken language, which certainly don't count as 'features', can almost certainly be disregarded in this way. This suggests that height specifications of loci could be compared not just to pronominal features, but also to co-speech gestures, and possibly other expressions - hence a debate which is only beginning.

(iii) Finally, the iconic examples discussed above primarily affected the vertical plane. Can the horizontal plane give rise to iconic effects too? Schlenker $2015 \mathrm{~b}$ revisits the cases of locative shift discussed above in (12), and argues that they too can give rise to highly iconic effects, although their analysis is still the subject of ongoing debates.

\section{Conclusion}

In sum, sign language data can bring two kinds of special insights into the semantics of anaphora. First, they arguably make visible indexing mechanisms that are usually covert in spoken language, with the result that some aspects of Logical Form can be more directly observed in sign language than in spoken language (an alternative analysis in terms of a non-standard mechanisms of agreement yields a somewhat different account of these facts, however). Second, these data suggest that rich iconic effects are found at the core of the logical engine of sign language.

Two conclusions could be drawn from the latter observation. One is that from this perspective spoken languages are 'defective' because their iconic component is so limited; thus if one wishes to investigate the full expressive power of natural language anaphora, one might be well inspired to start with signed rather than spoken languages. Alternatively, one may take the comparison between sign and spoken language to be imbalanced unless one investigates the latter in tandem with co-speech gestures, which clearly have a rich iconic potential as well; this is now a topic of active research at the interface between sign language and gesture research (Goldin-Meadow and Brentari 2015). 


\section{References}

Bahan, B., Kegl, J., MacLaughlin, D., \& Neidle, C. (1995). Convergent evidence for the structure of determiner phrases in American Sign Language. In L. Gabriele, D. Hardison, \& R. Westmoreland (Eds.), FLSM VI, Proceedings of the sixth annual meeting of the Formal Linguistics Society of MidAmerica (Vol. 2, pp. 1-12). Bloomington, IN: Indiana University Linguistics Club Publications.

Bhatt, Rajesh and Pancheva, Roumyana: 2006. Conditionals. In The Blackwell Companion to Syntax, M. Everaert and H.van Riemsdijk (eds.), Vol 1: 638-687. Boston and Oxford: Blackwell.

Bittner, Maria. 2001. Topical referents for individuals and possibilities. In: Proceedings of Semantics and Linguistic Theory XI (Rachel Hastings, Brendan Jackson, and Zsofia Zvolenszky, eds.), 36-55. CLC, Ithaca.

Cooper, Robin: 1983. Quantification and Syntactic Theory. Synthese Language Library 21.

Cuxac, Christian: 1999, French SIHn Language: Proposition of a Structural Explanation by Iconicity. In A. Braort et al. (eds), Gesture-based Communication in Human-Computer Interaction. Springer, pp. 165-184

Dekker, Paul: 2004. Cases, adverbs, situations and events. In H. Kamp \& B. Partee (Eds.), Context dependence in the analysis of linguistic meaning. Amsterdam: Elsevier.

Elbourne, Paul: 2005. Situations and individuals. Cambridge, MA: MIT Press.

Emmorey, Karen: 2002. Language, cognition, and the brain: Insights from sign language research. Mahwah, NJ: Erlbaum

Emmorey, Karen : 2014. Iconicity as structure mapping. Phil. Trans. R. Soc. 369(1651). http://dx.doi.org/10.1098/rstb.2013.0301

Evans, Gareth: 1980. Pronouns, Linguistic Inquiry, 11(2), 337-362.

Finer, Daniel: 1985, The syntax of switch-reference. Linguistic Inquiry 16, 1: 35-55

Geach, Peter. 1962. Reference and generality. An examination of some medieval and modern theories. Ithaca/ NY:Cornell University Press.

Goldin-Meadow, Susan and Brentari, Diane: 2015, Gesture, sign and language: The coming of age of sign language and gesture studies. Manuscript, University of Chicago.

Greenberg, Gabriel: 2012. Pictorial Semantics. Manuscript, UCLA.

Groenendijk, Jeroen \& Stokhof, Martin: 1991. Dynamic predicate logic. Linguistics and Philosophy, 14(1), 39-100.

Heim, Irene: 1982. The semantics of definite and indefinite noun phrases. Ph.D. Dissertation, University of Massachusetts, Amherst.

Heim, Irene: 1990. E-type pronouns and donkey anaphora. Linguistics and Philosophy, 13, 137-177.

Heim, Irene: 1991, 'The first person', Class handouts, MIT.

Heim, Irene: 2008. Features on bound pronouns. In Daniel Harbour, David Adger, Susana Bejar (eds), Phi-theory: Phi-features across modules and interfaces, Oxford University Press.

Heim, Irene \& Kratzer, Angelika: 1998. Semantics in Generative Grammar. Oxford: Blackwell.

Jacobson, Pauline: 1999. Towards a variable free semantics. Linguistics and Philosophy 22:117-184.

Jacobson, Pauline: 2012, Direct Compositionality and 'Uninterpretability': The Case of (Sometimes) 'Uninterpretable' Features on Pronouns. Journal of Semantics, 29: 305-343

Hockett, Charles F.: 1966, What Algonquian is Really Like. IJAL 31 (1): 59-73. JSTOR 1263449.

Iatridou , Sabine: 1994. On the contribution of conditional Then. Natural Language Semantics, 2 , 171 -199 .

Izvorski , Roumyana: 1996. The syntax and semantics of correlative proforms . In K . Kusumoto , (ed.), Proceedings of NELS 26 . Amherst, MA : GLSA

Kamp, Hans: 1981. A theory of truth and semantic representation. In J. A. G. Groenendijk, T. M. V. Janssen, \& M. J. B. Stokhof (Eds.), Formal methods in the study of language. Amsterdam: Mathematical Centre.

Koulidobrova, Elena: 2011, SELF: Intensifier and 'long distance' effects in American Sign Language (ASL). Manuscript, University of Connecticut.

Kratzer, Angelika: 1991, Modality. In Semantics: An International Handbook of Contemporary Research, edited by Arnim von Stechow \& Dieter Wunderlich, pp. 639-650. Berlin: de Gruyter.

Kratzer, Angelika: 2009. Making a pronoun: Fake indexicals as windows into the properties of pronouns. Linguistic Inquiry 40(2): 187-237.

Kuhn, Jeremy: to appear, ASL Loci: Variables or Features? To appear in Journal of Semantics.

Liddell, Scott K.: 2003. Grammar, Gesture, and Meaning in American SIHn Language. Cambridge: Cambridge University Press.

Lillo-Martin, Diane: 1991. Universal grammar and American Sign Language: Setting the null argument parameters. Dordrecht: Kluwer Academic Publishers. 
Lillo-Martin, Diane \& Klima, Edward S.: 1990. Pointing out Differences: ASL Pronouns in Syntactic Theory. In Susan D. Fischer \& Patricia Siple (Eds.), Theoretical Issues in Sign Language Research, Volume 1: Linguistics, 191-210. Chicago: The University of Chicago Press.

Lillo-Martin, Diane and Meier, Richard P.: 2011, On the Linguistic Status of 'Agreement' in Sign Languages. Target article, Theoretical Linguistics 37, 95-141.

Neidle, Carol, et al.: 2000, The Syntax of American SIHn Language: Functional Categories and Hierarchical Structure. MIT Press.

Nouwen, Rick: 2003, Plural pronominal anaphora in context. Number 84 in Netherlands Graduate School of Linguistics Dissertations, LOT, Utrecht.

Partee , B. 1973 : Some structural analogies between tenses and pronouns in English. The Journal of Philosophy, $70,601-609$.

Quine, Williard V.: 1960. Variables explained away. Proceedings of the American Philosophical Society 104(3): 343-347.

Sandler, Wendy \& Lillo-Martin, Diane: 2006, Sign Language and Linguistic Universals. Cambridge University Press.

Schlenker, Philippe: 1999. Propositional Attitudes and Indexicality: a Cross-Categorial Approach. Doctoral dissertation, MIT.

Schlenker, Philippe: 2003. A Plea for Monsters, Linguistics \& Philosophy 26: 29-120.

Schlenker, Philippe: 2004. Conditionals as definite descriptions (a referential analysis). Research on Language and Computation , 2, 3 , 417-162 . Stone , M . 1997 : The anaphoric parallel between modality and tense, IRCS Report $97-06$, Philadelphia, PA : University of Pennsylvania Press.

Schlenker, Philippe: 2011a. Iconic Agreement. Theoretical Linguistics 37(3-4): 223-234.

Schlenker, Philippe: 2011b. Donkey Anaphora: the View from Sign Language (ASL and LSF). Linguistics and Philosophy 34(4): 341-395.

Schlenker, Philippe: 2011c. Quantifiers and Variables: Insights from Sign Language (ASL and LSF). In Partee, B.H., Glanzberg, M., \& Skilters, J. (eds), Formal Semantics and Pragmatics: Discourse, Context, and Models. The Baltic International Yearbook of Cognition, Logic and Communication, Vol. 6, 2011.

Schlenker, Philippe: 2013a. Temporal and Modal Anaphora in Sign Language (ASL). Natural Language and Linguistic Theory 31(1): 207-234.

Schlenker, Philippe: 2013b. Anaphora: Insights from Sign Language (Summary). In L'Interface langage-cognition The Language-cognition Interface. Actes du 19 e Congrès International des Linguistes, Genève, 22-27 juillet 2013, editorial coordination by S. R. Anderson, J. Moeschler and F. Reboul. Droz.

Schlenker, Philippe: 2014a. Iconic Features. Natural Language Semantics 22(4): 299-356.

Schlenker, Philippe: 2014b. Featural Variables. In The Art and Craft of Semantics. A Festschrift for Irene Heim. Vol. 2. Ed. by L. Crnic and U. Sauerland. MIT Working Papers in Linguistics 71.

Schlenker, Philippe: 2015a. Visible Meaning: Sign Language and the Foundations of Semantics. Manuscript, Institut Jean-Nicod and New York University (submitted).

Schlenker, Philippe: 2015b. Gestural Presuppositions. To appear in Snippets.

Schlenker, Philippe, Lamberton, Jonathan \& Santoro, Mirko: 2013. Iconic Variables. Linguistics \& Philosophy 36(2): 91-149.

Schlenker, Philippe and Mathur, Gaurav: 2013, A Strong Crossover Effect in ASL (squib). Snippets 27, September 2013, doi: 10.7358/snip-2013-027-schl

Sharvit, Yael: 2008. The puzzle of free indirect discourse. Linguistics and Philosophy 31: 353 - 395.

Stechow, Arnim von: 2004. Binding by Verbs: Tense, Person and Mood under Attitudes. In The Syntax and Semantics of the Left Periphery, eds. Horst Lohnstein and Susanne Trissler, $431-488$. Berlin - New York: Mouton de Gruyter.

Stone, M. 1997: The anaphoric parallel between modality and tense, IRCS Report 97 - 06 , Philadelphia, PA : University of Pennsylvania Press.

Taub, Sarah F.: 2001, Language from the body. Cambridge University Press.

Winston, E. (1995). Spatial mapping in comparative discourse frames. In K. Emmorey \& J. S. Reilly (Eds.), Language, gesture, and space (pp. 87-114). Hillsdale, NJ: Lawrence Erlbaum. 